\title{
Building a Window to the Sea: Ocean Research Interactive Observatory Networks (ORION)
}

\author{
BY OSCAR SCHOFIELD AND MARGARET K. TIVEY
}

\section{INTRODUCTION}

For centuries, oceanographers have relied on data and observations about the ocean and the seafloor below gathered from ships during cruises of limited duration. This expeditionary research approach has resulted in major advances in understanding global ocean circulation, the energy associated with mesoscale circulation, plate tectonics, global ocean productivity, and climate-ocean coupling. These and many other successes have expanded our view of Earth and ocean processes, and have demonstrated a need for sampling strategies spanning temporal and spatial scales not effectively carried out using ships. To address this observational gap, community efforts in the United States consistently have recommended that funding

Oscar Schofield (oscar@imcs.rutgers.edu) is Associate Professor, Coastal Ocean Observation Laboratory, Institute of Marine and Coastal Sciences, Rutgers University, New Brunswick, NJ. Margaret K. Tivey is Associate Scientist, Department of Marine Chemistry and Geochemistry, Woods Hole Oceanographic Institution, Woods Hole, MA. agencies support development of the capability to maintain a continuous sampling and monitoring presence in the ocean.

\section{THE NEED FOR A CONTINUOUS}

\section{PRESENCE IN THE OCEAN}

Current inability to sample the oceans coherently is a critical problem. It can introduce biases, compromising our understanding of a large range of significant ocean processes. For example, the role that large storms play in enhancing the productivity in the oligotrophic (nutrient-poor) open ocean was not appreciated until they were sampled by fortuitously timed open-ocean cruises (Glover et al., 1988) and robust biooptical moorings capable of providing measurements when ships could not remain at sea (Dickey et al., 1998). Documentation of storm-induced changes has helped reconcile the widely disparate estimates in global ocean productivity based on either discrete biology rate measurements (Platt, 1984) or bulk chemical budgets (Schulenberger and Reid, 1981; Jenkins and Goldman, 1985). Similar examples exist from all disciplines in oceanography. As a result, attention has turned to the development of a sustained and continuous presence in the ocean. The relevance of this approach is validated by the successes of the Long Term Ecological Research program (information available online at http://lternet.edu/) and the few available oceanic time-series data sets (McGowan et al., 1998; Karl and Lukas, 1996; Michaels and Knapp, 1996) that have documented the importance of high-frequency annual and decadal processes.

\section{THE OPPORTUNITY TO CREATE}

\section{AN INTEGRATED OCEAN}

\section{OBSERVATORY NETWORK}

Myriad community workshops and reports (Table 1) in the United States have called for populating the ocean with an array of in situ fixed and mobile platforms that will complement the advancing capabilities of remote sensing and numerical modeling. In situ technologies have matured to the point where they are ready to be deployed as part of an integrated ocean observing network (National Research Council, 2003). The U.S. oceanographic community, in response to workshop recommendations (Table 1), 


\begin{tabular}{|l|l|}
\hline Workshop and/or Report Title & Year \\
\hline International Conference on the Ocean Observing System for Climate & 1999 \\
\hline Developing Submergence Science in the Next Decade (DESCEND) & 1999 \\
\hline Symposium on Seafloor Science & 2000 \\
\hline Ocean Sciences at the New Millennium & 2001 \\
\hline Integrated and Sustained Ocean Observing System Workshop & 2002 \\
\hline Office of Naval Research/Marine Technology Society Buoy Workshop & 2002 \\
\hline Scientific Cabled Observatories for Time-Series (SCOTS) & 2002 \\
\hline Coastal Ocean Processes and Observatories: Advancing Coastal Research & 2002 \\
\hline Autonomous and Lagrangian Platforms and Sensors (ALPS) & 2003 \\
\hline Implementation Plan for the DEOS Global Network of Moored-Buoy Observatories & 2003 \\
\hline NEPTUNE Pacific Northwest Workshop & 2003 \\
\hline Biological and Chemical Instrumentation in the Ocean & 2003 \\
\hline Links between OOI and IODP Workshop & 2003 \\
\hline REgional Cabled Observatory Network (of Networks) (RECONN) & 2003 \\
\hline Technical Issues Related to Cable Re-use & 2003 \\
\hline Coastal Observatory Research Arrays (CORA): A Framework for Implementation Planning & 2003 \\
\hline Ocean Research Interactive Observatory Networks (ORION) & 2004 \\
\hline
\end{tabular}

Table 1. A list of some of the many workshops and/or reports that have called for sustained ocean observations. All propose building permanent observing capabilities in the world's oceans.

is now poised to gain a substantial investment for the infrastructure through a variety of U.S. federal initiatives. The common goals of these science plans are to maintain a permanent presence in the ocean, to collect sustained, spatially resolved time-series measurements, and to deliver data back to scientists on land in real time. It will be possible to access data collected from integrated and diverse sensor packages mounted on moorings, seafloor cables, satellites, aircraft, drifters, and autonomous vehicles. This sustained presence will complement traditional ship-based research, permitting adjustments to sampling strategies.

Many of the technical elements of pro- posed observatories have been highlighted at workshops focused around specific technologies. For example, the Scientific Cabled Ocean Time Series (SCOTS; Glenn and Dickey, 2003) workshop focused on science issues that could be addressed using seafloor cable networks, while the Autonomous and Lagrangian Platform and Sensors (ALPS; Rudnick and Perry, 2003) workshop focused on the utility of mobile vehicles and drifters. While these focused planning efforts were needed to identify critical technical and scientific issues, and to exchange ideas within specific communities, they did not allow for effective communication of information across groups, or for coordination of a large- scale strategy for ocean observatories. This compartmentalization was also mirrored in the science planning efforts, with different workshops focused on different spatial scales (e.g., global, regional, coastal).

\section{OCEAN RESEARCH INTERACTIVE OBSERVATORY NETWORKS (ORION)}

To coordinate a large-scale strategy for ocean observatories, and to ensure that the growing number of research observatory efforts complement and leverage off of each other, the U.S. National Science Foundation (NSF) established the Ocean Research Interactive Observatory Networks (ORION) Program Office in March 2004. ORION provides the "big tent" for all aspects of the construction and operation of an integrated ocean observatory network. It also works to facilitate cooperation with other NSF initiatives that lie outside the Geosciences Directorate, and with those at other federal agencies. ORION office responsibilities include management of the ORION program, establishment of a community advisory structure, facilitation of community outreach, oversight of network construction, and operation and maintenance of the network (Clark and Isern, 2003). Given this charge, ORION has an all-encompassing view of research-based, ocean-observing efforts, ensuring seamless integration of the observing system's diverse elements.

One of the first responsibilities of the ORION Program Office is to prepare for the Ocean Observatory Initiative (OOI), which will provide infrastructure funds from NSF's Major Research Equipment and Facilities Construction (MREFC) account ( $\sim 250 \mathrm{M})$. The OOI has been listed in the President's budget request to Congress as a high-priority item for fiscal year 2006 (October 1, 2005 through September 30, 2006). The OOI has 
three major elements: (1) re-locatable deepsea buoys that can be deployed in harsh environments, such as the Southern Ocean, (2) a regional cabled network consisting of interconnected monitoring sites on seafloor spanning scientifically interesting geological and oceanographic regions, and (3) a network of long-duration, continental time series, cross-shore observatories augmented with re-locatable instrument arrays. Potential related initiatives such as ALPS could provide the capability to develop fleets of autonomous drifters or vehicles to provide a Lagrangian picture (a frame of reference that moves with the fluid) to complement Eulerian data (data that are a function of space and time) provided by the OOI fixed instrumentation. ORION's success will in part be measured by how well these diverse observational communities can cooperate to enable each other's successes.

\section{THE 2004 ORION WORKSHOP}

As a first step in getting the ORION office established, the Dynamics of Earth and Ocean Systems (DEOS) Steering Committee, with support from NSF, convened an open community workshop in early January 2004 in San Juan, Puerto Rico. Over 300 participants attended the meeting from eight countries, with 110 academic, federal, and industrial entities represented. The ORION Workshop was organized with the goal of formulating science, technology, and education and outreach priorities for the OOI, which would allow definition of appropriate observational arrays. Compared with past workshops, participants were not constrained by a specific scientific focus (solid Earth, air-sea fluxes, or marine food webs), geographical footprint (coastal, regional, or global) or observational platform (cables or autonomous underwater vehicles). Prior to the workshop, participants had Web access to the agenda, background information papers, and an evolving list of science questions that would be discussed by various groups during the workshop. The first day on site was devoted to science, technology, and education overview talks, a poster session, and a panel discussion of broader ocean-observing activities with representatives from the NSF, the National Oceanic and Atmospheric Administration, the Office of Naval Research, Ocean.US, and the National Aeronautics and Space Administration. The remainder of the workshop then focused on highly interactive small-group discussions of science, technology and engineering, and education and outreach issues. The relatively large (>35 participants) technology and education and outreach groups had dual tasks: to send pairs of educators or engineers to join and participate in science small-group discussions, and to periodically reconvene to tackle technology or education and outreach issues that arose during the science discussions. The goal was to weave technology and educational opportunities into the initial observatory network design. The smaller science working groups, all with fewer than 20 participants, met to discuss how access to two-way communication, sustained data recording, and power could be used to tackle questions related to Earth structure, plate dynamics, fluid-rock interactions, airsea fluxes, biogeochemical cycles from the rivers to the continental slope, benthic water-column coupling, global ocean circulation and climate, global biogeochemistry, small-scale mixing and nearshore processes, marine food webs, impact of humans on marine ecosystems, and marine ecology. The groups were encouraged to mix and evolve the science focus as desired. These groups were asked to identify: (1) the most exciting research opportunities that could be provided by ORION but could not be addressed using traditional assets and techniques, (2) the spatial and temporal scales required, (3) the priority measurements and parameters needed, (4) the education and outreach opportunities, and (5) a timeline for addressing the question or experiment.

\section{ORION WORKSHOP RESULTS}

Currently, the results of all of the working group discussions are being compiled in a workshop report, however, we take the opportunity in this paper to provide an introduction to these conference discussions. Within the science and technology working groups, several common themes emerged, including the need for high-frequency, continuous, time-series measurements in broad-scale spatial arrays. These data would allow interdependencies of physical, biological, chemical, and geological variables to be studied, and would provide coherent data to enable modeling efforts. Common scientific questions, though aimed at different environments within the ocean, also emerged, including:

- How significant are stochastic processes in structuring ocean physics, chemistry, biology, and geology? Most researchers readily acknowledge that episodic events likely have a large influence on ocean processes, yet we have been unable to adequately sample these events and effectively quantify their relative significance (Figures 1 and 2). ORION is required to provide the tools to enable scientists to understand the role of stochastic processes in the oceans.

- What is the relative importance of non-periodic (secular) versus cyclical processes in driving observed variability in the ocean? To understand the potential changes in 


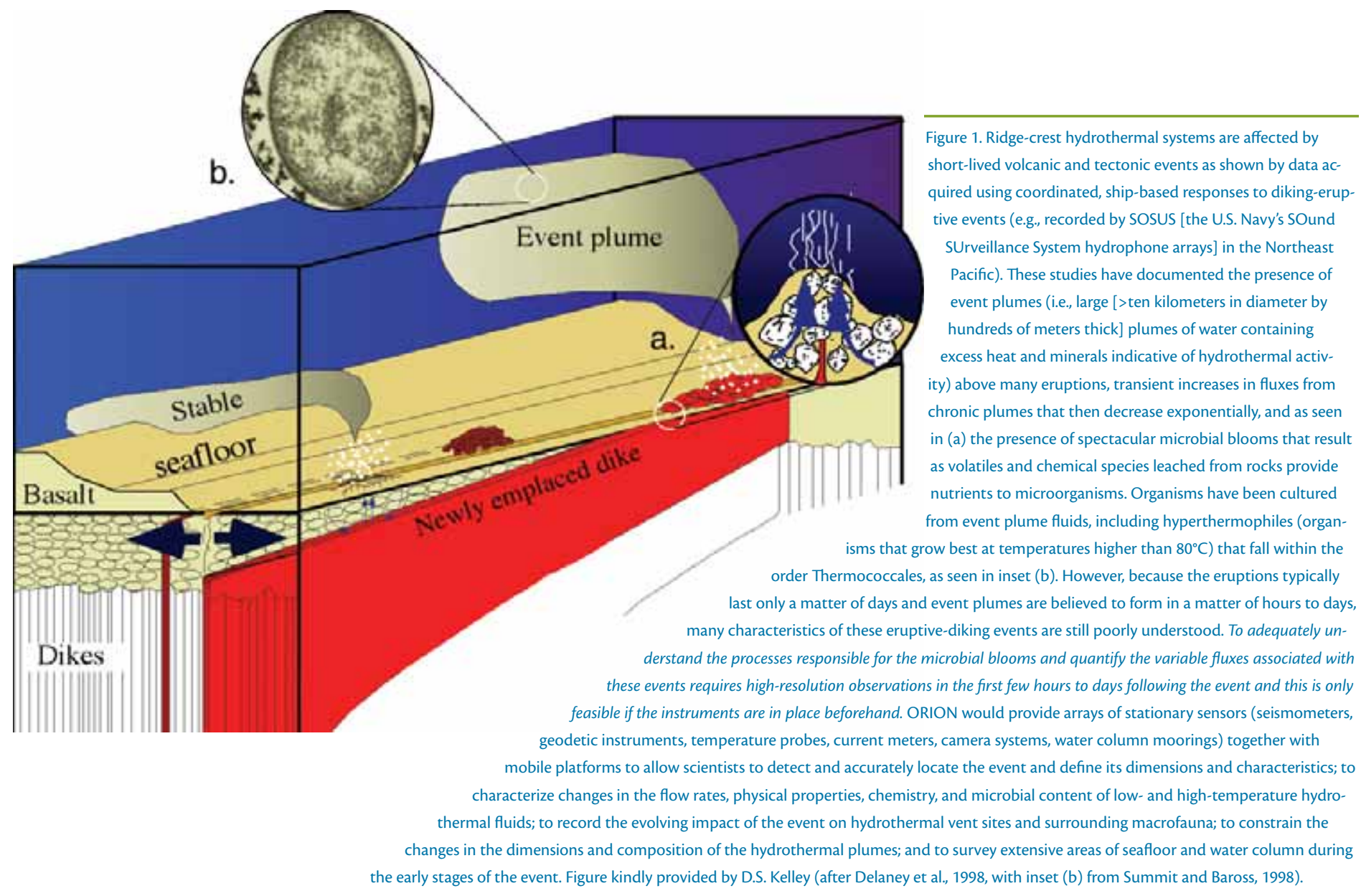

Photosynthetic Pigment Time Series for Station Aloha Region HOT in situ and SeaWIFS Satellite-derived data
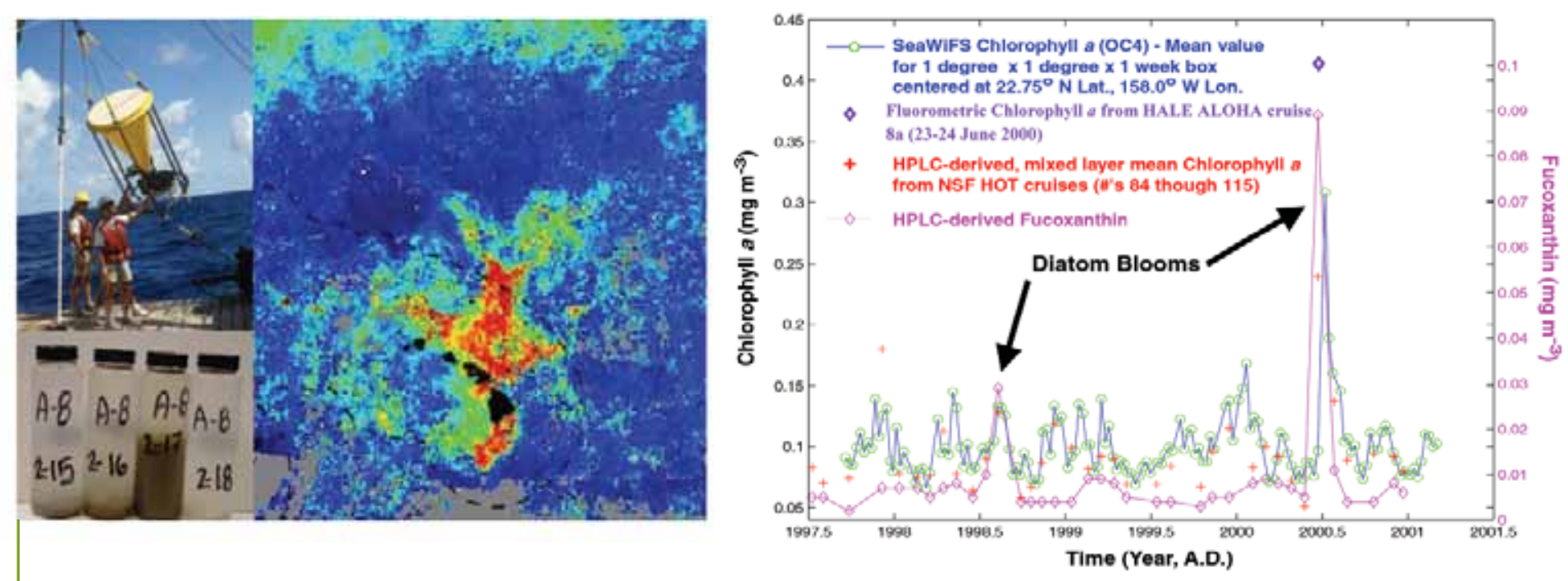

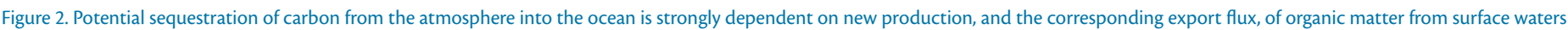

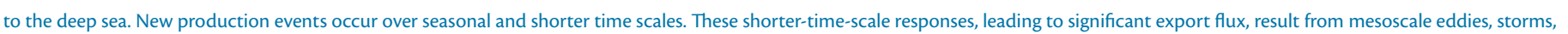

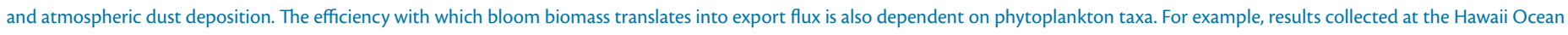

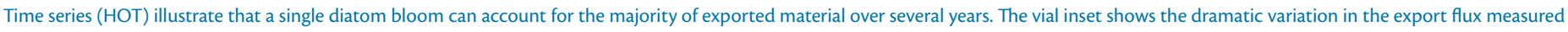

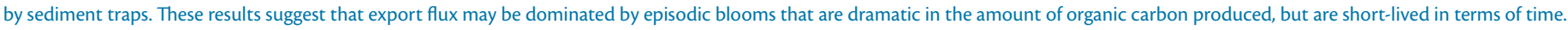

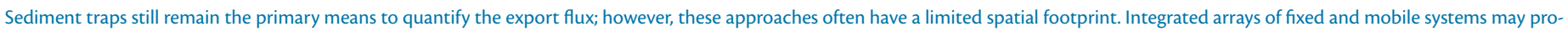

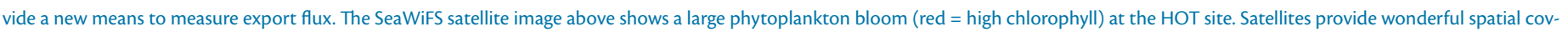

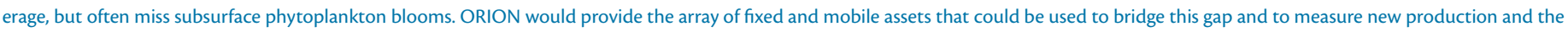

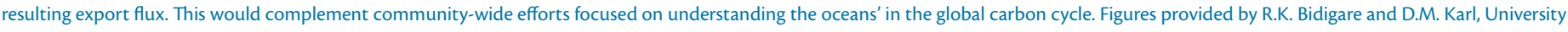
of Hawaii. The HOT team is also gratefully acknowledged. 
the world's oceans, the importance of annual, multi-year, and decadal cycles needs to be judged against those of secular (non-periodic) changes analogous to the increasing trend in atmospheric $\mathrm{CO}_{2}$. This requires a comprehensive understanding of the fundamental mechanisms that underlie cyclical processes in the world's ocean, and a sustained spatial time series obtained by ORION (Figure 3).

- How are human activities affected by the oceans, and how are the oceans affected by human activities? What are the potential effects on humankind from the observed changes in the oceans? The oceans have always affected people living in coastal areas (Figure 4). In addition, humans are exerting an increasingly large influence on the ocean, but the consequences of this activity have yet to be defined (Figure 5). Additionally, any changes in the oceans may have negative consequences for humans. Understanding the influence of human activities requires comprehending the interplay of ocean physics, chemistry, geology, and biology. This requires a comprehensive view spanning local to global scales, which will be provided by an integrated ocean-observing network. The education and outreach group identified an overarching goal to increase student and public awareness, understanding, and appreciation of the oceans in the Earth system; strengthen science and technology education; and expand society's understanding and appreciation of the oceans' life-giving processes that sustain us and support our well-being. Their specific recommendations include:

- create an office to coordinate ORION education and communications. This office would provide to the ORION community education and dissemination expertise that is impractical or inefficient to imbed in individual projects.

- include a data management and content translation facility with expertise in translating and preparing scientific and technological content for use by educators and communications professionals.

- promote the development and diversity of the ocean-related workforce.

- stimulate the young and old to understand and appreciate the vital role of the ocean
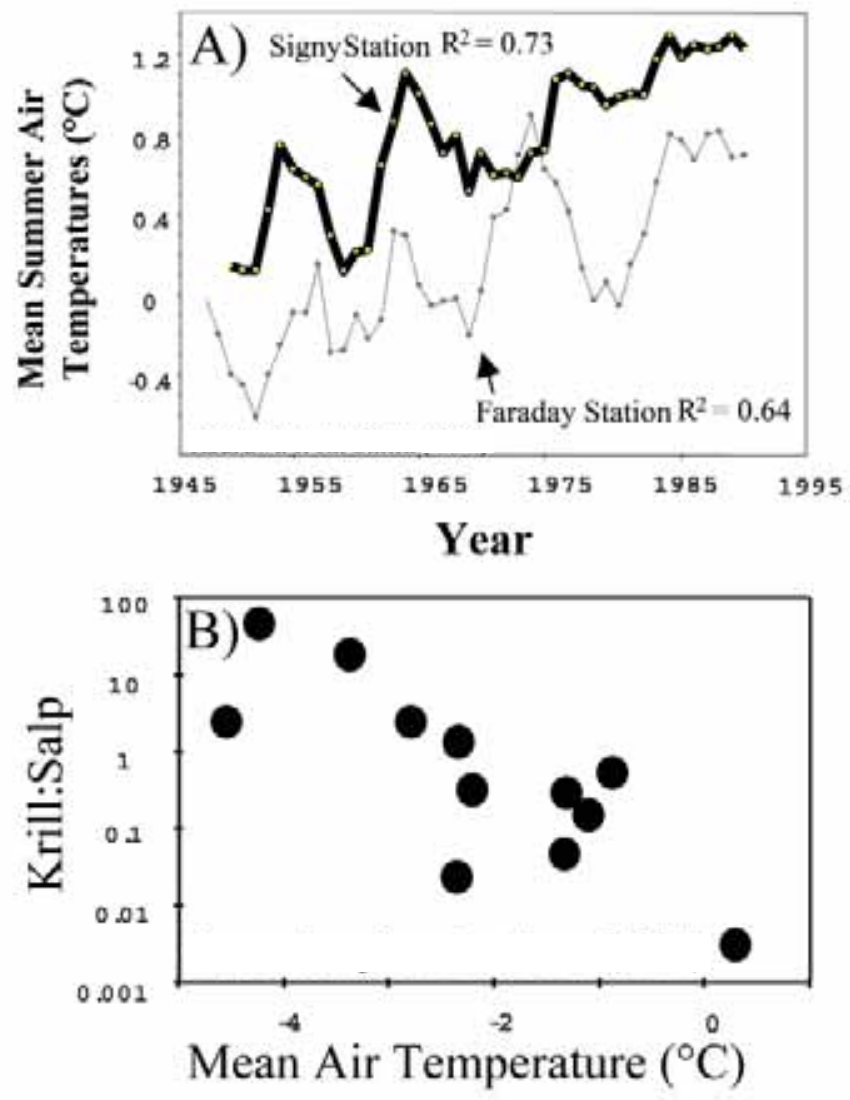

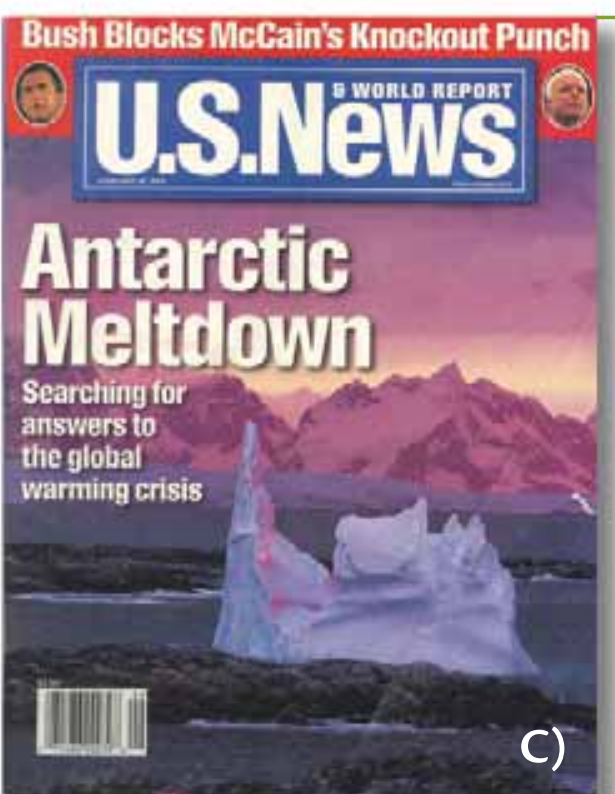

Figure 3. (A) Time series of air temperatures from data collected by the British Antarctic Survey along the Antarctic

Peninsula. The warming trend over the past 50 years is one of the fastest on Earth. What proportion of this temperature change reflects secular (nonperiodic ) or cyclical processes given recent reports of multi-decadal cycles (Chavez et al., 2003)? While oceanic time series do exist, such as the successful thirteen-year Long-Term Ecological Research (LTER) program along the peninsula (more information at http:// iceflo.icess.ucsb.edu:8080/ice_hp.php), they are not long enough yet to allow underlying processes of the observed changes to be determined (redrawn from Smith, 1994). Inset (B) shows the relationship of the krill to salp ratio to the mean summer air temperatures along the Antarctic Peninsula (redrawn from Moline et al., in press, based on data from Loeb et al, 1997). The shift to a gelantious second producer has profound implications for the Antarctic ecosystem. The mechanisms underlying this shift are being debated. Competing hypotheses will require a spatially extensive observational array that couples acoustical, bio-optical, physical, and atmospheric data. In (C) we see a great opportunity to engage the general public in the global change debate, which is a visible news item in the popular press (reprinted with permission, copyright 2000, U.S. News \& World Report). ORION will need to facilitate outreach by providing an avenue for oceanographers to communicate their scientific discoveries to the general public and news media. 


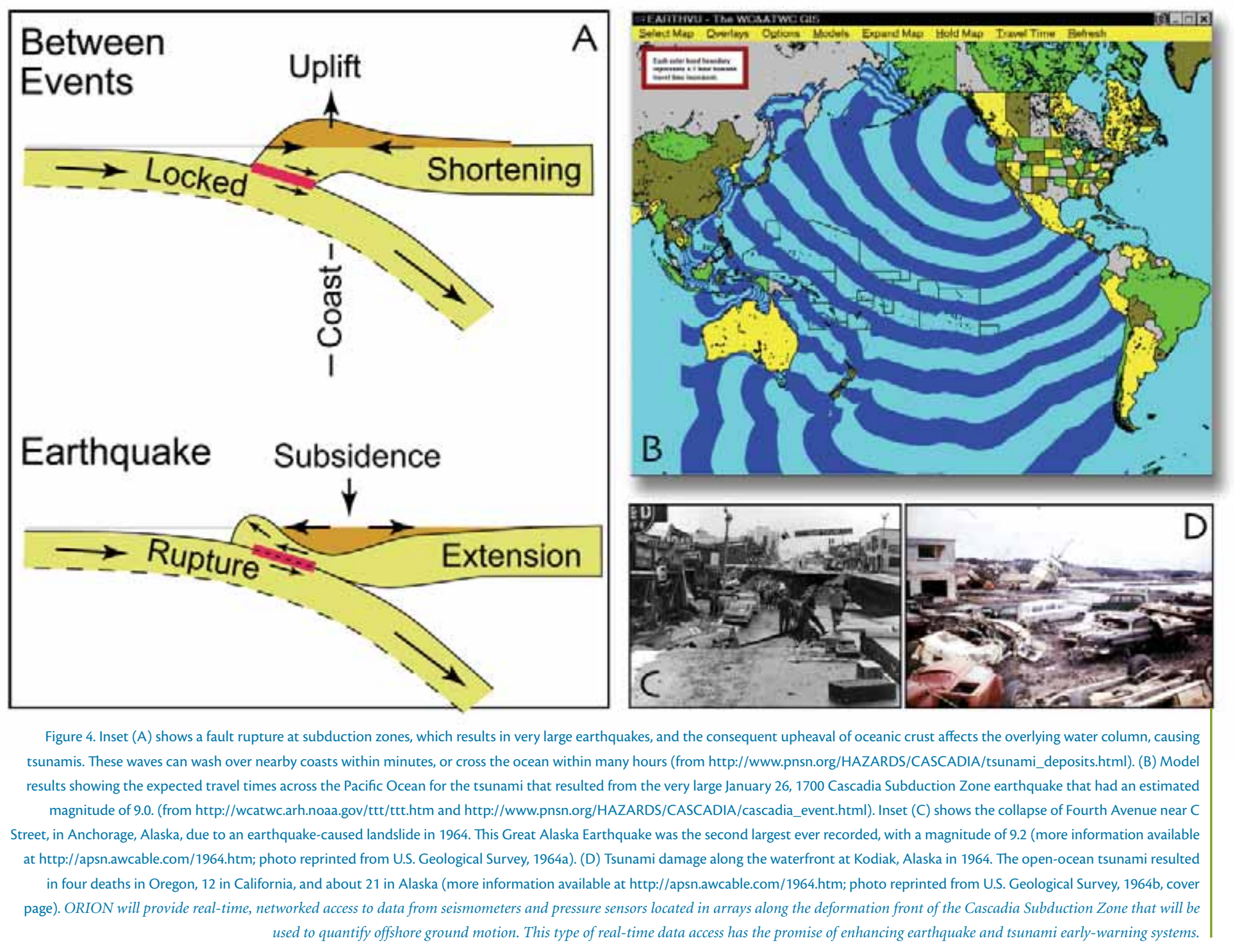

in the Earth system, and its importance to well-being.

Specific recommendations from the technology and engineering group include:

- use common engineering methods to develop and operate OOI facilities. OOI observatories will require large and complex facilities for implementation and operation. Their development and operation require use of engineering methods, which while familiar in the physics community, are not commonly employed in the oceano- graphic world. In particular, the disciplines of project management and system engineering will be essential to the success of large-scale engineering activities.

- employ a careful process to permit the engineering community to understand science needs. This is the "input" to the more formal engineering process described above. Science needs could be extracted from "use cases," which in turn would build on the science plan. These use cases would allow the extraction of "functional requirements," which in turn would allow the development of engineering specifications. The vital importance of this part of the process is clear because no engineering process, no matter how sophisticated, can overcome being given the wrong requirements.

- develop the capability for event response adaptive sampling using ocean observatories.

- promote collaboration between ORION and the information-technologies comput- 
er-science community. It will be important for ORION to leverage strong initiatives at NSF and at other federal agencies for both funding and scientific/engineering expertise.

- continue development of acoustics and optics, which are especially critical for biological and chemical oceanographers. ORION will be much stronger if it reaches out to these communities, especially as NSF historically has not invested heavily in acoustics or optics research.

\section{CHALLENGES TO OVERCOME}

As with all great endeavors, significant challenges need to be overcome to succeed in gaining a sustained and continuous presence in the ocean. Some of these were identified by the science, education, and engineering attendees in Puerto Rico, and all will require a concerted and proactive effort by the U.S. ORION effort. Identified challenges include:

- vigorously pursuing international partnerships. The ORION Program Office should work with countries that already have extensive observatory efforts (e.g., Canada, Japan, and the countries of the European Economic Union) to ensure that all ocean-observing networks are fully integrated. Some of the international partnerships are mature. For example, the proposed North-East Pacific Time-series Undersea Networked Experiments (NEPTUNE) represents a formal partnership between Canada and the United States, with Canada already having received funding on the order of $\$ 31.9$ million from the Canada Foundation for Innovation and \$30.5 million from the British Columbia Knowledge Development Fund. Continuing and building partnerships such as NEPTUNE is critical to a successful ocean-observatory strategy.
- providing an effective voice to help ensure that all ocean-observing efforts for the United States complement and augment one other. As highlighted in the recently released draft report by the U.S. Commission on Ocean Policy Ocean Commission Report (available on-line at: www.oceancommission.gov/), funding for oceanographic research is spread throughout many agencies in the United States government, thus complicating the coordina- tion of ongoing efforts. A high priority in the near term is for ORION to actively engage the Integrated Ocean Observing System (IOOS) regional associations.

- developing education programs in parallel with the observatory construction. These programs should build upon existing efforts and capabilities and make extensive use of partnerships with the ORION science and technology community, and with established education organizations.

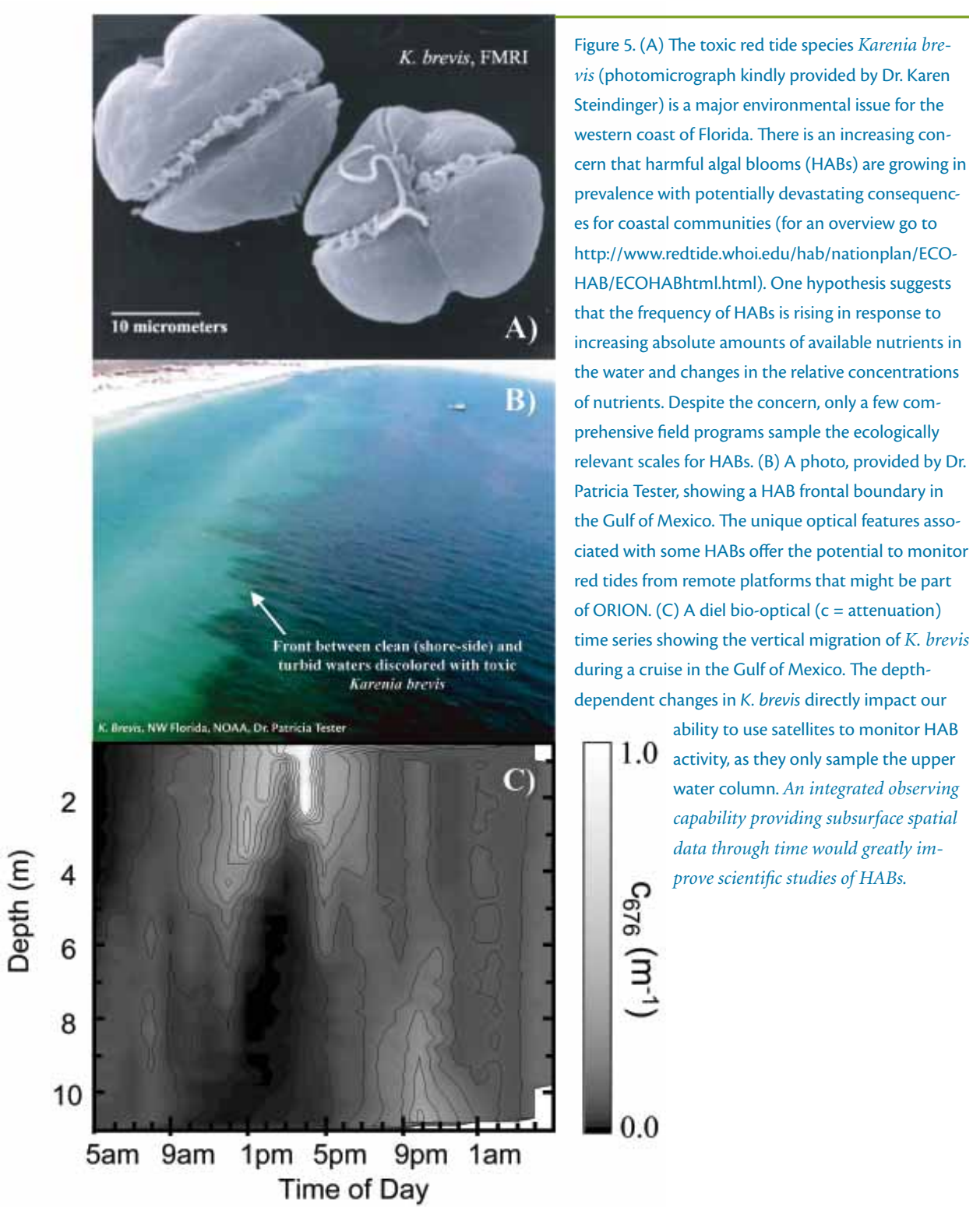


- developing a clear and transparent procedure for scientists to gain access to the observatory.

- pursuing a system engineering approach for developing the OOI given the scale of the proposed observatory network. For example, trans-oceanic cables received sustained systems engineering before cable was laid in the oceans. System engineering plans should clearly lay out OOI's phased implementation.

- building a management structure that ensures that the science community has sufficient control of observatory infrastructure to permit execution of bold and innovative experiments not yet conceived.

Oceanography has had great success with individual and small research groups conducting focused research efforts. As the community embarks on these large interdisciplinary efforts, it must also safeguard individual research efforts. The core science budgets at NSF Division of Ocean Sciences must be protected so that the new ocean observing initiatives do not come at the expense of individual researchers conducting their research. Thus the call by the U.S. Commission on Ocean Policy to double the amount of money for ocean research must be vigorously pursued.

\section{ACKNOWLEDGEMENTS}

We thank the extensive input provided by Jim Bellingham, Robert Bidigare, Ken Brink, Francisco Chavez, Kendra Daly, John Delaney, Robert Detrich, Zoe Finkel, Scott Glenn, Dave Karl, Blanche Meeson, John Orcutt, and William Wilcock. We are most grateful to the attendees of the ORION meeting in Puerto Rico for their enthusiasm, humor, and intellectual energy. MKT is grateful for support from a WHOI Deep Ocean Exploration Institute fellowship. 四

\section{REFERENCES}

Chavez, F.P., J. Ryan, S.E. Llutch-Cota, and M.C. Niquen, 2003: From anchovies to sardines and back: Multidecadal change in the Pacific ocean. Science, 299, 217-221.

Clark, H.L. and A. Isern, 2003: The OOI and the IOOSCan they be differentiated? An NSF perspective. Oceanography, 16(4), 20-21.

Delaney, J.R., D.S. Kelley, M.D. Lilley, D.A. Butterfield, J.A. Baross, W.S.D. Wilcock, R.W. Embley, and M. Summit, 1998: The quantum event of oceanic crustal accretion: Impacts of diking at mid-ocean ridges. Science, 281, 222-230.

Dickey, T., D. Frye, J. McNeil, D. Manov, N. Nelson, D. Sigurdson, H. Jannasch, D. Siegel, T. Michaels, and R. Johnson, 1998: Upper-ocean temperature response to Hurricane Felix as measured by the Bermuda Testbed Mooring. Mon. Weather Rev., 126, 1,195-1,201.

Glenn, S.M., and T.D. Dickey, eds., 2003: SCOTS: Scientific Cabled Observatories for Time Series, National Science Foundation Ocean Observatories Initiative

\section{Books Received for Review}

- Biogeochemistry of Marine Systems

edited by Kenneth Black and Graham Shimmield (Blackwell Publishing, 384 pp.)

- Celebration of the World's Barrier Islands

by Orrin H. Pilkey (Columbia University Press, 400 pp.)

- The Machine in Neptune's Garden: Historical Perspectives on Technology and

the Marine Environment

by Helen M. Rozwadowski and David K. van Keurent (Science History Publications/USA, 371 pp.)

- Mass Balance of the Cryosphere: Observations and Modeling of Contemporary

and Future Changes

by Jonathan L. Bamber and Anthony J. Payne (Cambridge University Press, 662 pp.)

- Weather Cycles: Real or Imaginary?

by William James Burroughs (Cambridge University Press, 329 pp.) 